\title{
The Enhanced Carbamate Adsorption of Modified Bentonite with Coscinium fenestratum
}

\author{
S. Tha-in, H. A. Dau, and K. Dumri
}

\begin{abstract}
Pesticides daily pollutes soil and water in farmland and environment in ASEAN agricultural developing countries. In this study, pesticide adsorption was studied by bentonite modification, targeting the "organoclay" adsorbent in comparison to native bentonite, which was probably reported to adsorb agricultural pesticide. Commercial bentonite was modified with the berberine containing natural extract from Coscinium fenestratum; the local folk medicine in Thailand. The modified clay by extracted berberine was able to adsorb carbamate pesticide carbaryl with significant rate. HPLC analysis of residue carbaryl after adsorption process showed that it was up to $80 \%$ carbaryl adsorption when bentonite was modified by extracted berberine with ratio $1: 100(w / w)$, whereas commercial bentonite has showed at $70 \%$. Modified bentonite by $C$. fenestratum extract and berberine revealed by scanning electron microscopy showed that the different transform levels of this clay surface, herein, the highest carbaryl adsorption occurred when berberine/bentonite ratio for modification process was $1 / 200(\mathrm{w} / \mathrm{w})$. SEM results also demonstrated that the amount of berberine should be taken into consideration in term of bentonite modification for pesticide adsorption. Coscinium fenestratum plant will be further studied for its contribution to pesticide adsorption material in Thailand.
\end{abstract}

Index Terms-Bentonite, berberine, modification, carbaryl, adsorption, Coscinium fenestratum.

\section{INTRODUCTION}

The contamination of water and soil in farmland and surrounding environment by carbamate pesticide has been raising since it has become popular by its actual low mammalian oral and dermal toxicity [1]. Carbamates are easy to be washed out from leaves and soil, therefore, they may affect to the structure and functioning of the whole ecosystem [2].

Clay minerals have a great adsorption capability for cation and intensively specific surface areas involved with their small particles size. Previous reports have shown that, the modified clay minerals was used as an adsorbent for many different branches of industry e.g. in fluids [3], cement or

Manuscript received March 25, 2013; revised May 6, 2013. We wish to thank the National Research University Project under Thailand's office of the Higher Education Commission for financial support. And this work was supported in part by Postgraduate Education and Research Program in Chemistry, PERCH-CIC and Graduate school, Chiang Mai University.

$\mathrm{S}$. Tha-in is with the Graduate School in Chemistry program, Center of Excellence for Innovation in Chemistry and Department of Chemistry, Faculty of Science, Chiang Mai University, Chiang Mai, Thailand (e-mail: mint.suphara@gmail.com)

K. Dumri is with Center of Excellence for Innovation in Chemistry, Department of Chemistry, Faculty of Science, Chiang Mai University, Chiang Mai, Thailand.

H. A. Dau is with Faculty of Science and Agricultural Technology, Rajamagala University of Technology Lanna, Chiang Mai, Thailand (e-mail: dauhunganh@hotmail.com) drilling; in pharmaceutical e.g. nanocomposite [4],[5], removal pathogenic, virus [6], and toxin including heavy metal from aqueous solution [7], or an adsorbent for many hazardous pesticides and herbicides for eliminate pollutant from water and entirely systems [8],[9].

Bentonite is a type of clay minerals composes of mainly mineral of the smactite (Montmorillonite) group. It's hold the excellent plasticity, lubricity, high dry-bonding strength, low permeability and low compressibility makes bentonite important. The abundance of bentonite spreads in all continents and its low-cost makes it a strong alternative adsorbent for removal of pollutants. There are two types of bentonite; swelling-type or sodium bentonite and non-swelling-type or calcium bentonite [10], [11].

In this study, berberine (5,6-dihydro-9,10-dimethoxybenzo[g]-1,3 ben-zodioxolo[5,6-a] quinolizinium) $\left(\mathrm{C}_{20} \mathrm{H}_{18} \mathrm{NO}_{4}\right)^{+}$(Bbr) was used to modify bentonite. $\mathrm{Bbr}$ is the major pharmaceutical component in root and stem of the Thai "Ham" plant Coscinium fenestratum (Gaertn.) Colebr. (Menispermaceae) [12]. C. fenestratum extract has antifungal, antibacterial, antiyeast, and antiproliferative activities [13-15]. Berberine is the main isoquinoline alkaloid that was presented the natural organic monovalent cation in C. fenestratum, and involves the minor alkaloids such palmatine, tetrahydroplamatine, cerbanine and jatrorhizine, etc [16].

Recent studies have shown the reaction of berberine, (organic cation component), with commercial bentonite was suitable for the pretreatment of industrial effluents e.g. winery effluents and brine effluents. The expanding of the basal spacing of the smectite [17] and the adsorption modification of anthocyanins [18]. The combination between berberine and bentonite might be promising for environmental applications such as elimination of pesticides or herbicides [19].

This report purposed the production of low-cost "organoclay" adsorbents to enhance the adsorption of carbamate pesticide carbaryl; C. fenestratum extract was prepared to modify commercial bentonite in comparison to standard berberine-modified bentonite. High performance liquid chromatography (HPLC) was used to determine the residue of carbaryl after adsorption process and scanning electron microscope of modified bentonite was studied.

\section{Procedure}

\section{A. Materials}

The bentonite powder was purchased from Union Science Co., LTD. (Chiang Mai, Thailand). Sodium bentonite was produced by ion-exchange of calcium-bentonite (Ca-Bent) with sodium chloride $(\mathrm{NaCl})$. Na-Bent product was washed 
by deionized water for few times and dried to eliminate $\mathrm{Cl}^{-}$at $105^{\circ} \mathrm{C}$. Dried stems of C. fenestratum were provided by herbal medicine store in Chiang Mai, Thailand. Berberine chloride $(\mathrm{BbrCl})$ was purchased from Sigma-Aldrich (Bangkok, Thailand). Standard carbamate pesticide carbaryl was kindly supplied by Pesticide Residue Analytical Laboratory (Royal Project Foundation, Chiang Mai, Thailand).

\section{B. Sample Extraction and Precipitation}

Stems of $C$. fenestratum were chopped to small pieces about $0.5-1 \mathrm{~cm}$. Maceration extraction was performed in vase by adding $100 \mathrm{~g}$ of $C$. fenestratum into $300 \mathrm{ml}$ ethanol for 3 days by still not disturb. The extract was filtered to remove the plant residue following by addition of $\mathrm{NaCl} 1 \mathrm{~g}$ to precipitate the alkaloid content. It was dried at $60^{\circ} \mathrm{C}$ for a day to eliminate the ethanol. The remaining $\mathrm{NaCl}$ in the precipitate was removed by washing with deionized water. Precipitate (Alk) was collected by centrifugation at $4000 \mathrm{rpm}$, for $10 \mathrm{~min}$, at room temperature. It was dried at $60^{\circ} \mathrm{C}$ overnight and kept in desiccators.

\section{Determination of Berberine in Alk Extract}

Alk precipitate was firstly identified as an alkaloid by using dragendorff's reagent [20]; HPLC was used to confirm the Alk precipitate that contains berberine compound in extract. HPLC analysis was performed by Agilent 1100 HPLC system equipped with a various wavelength detector (VWD). The separation was used on a HP hypersil C18 column (125 mm x $4.6 \mathrm{~mm}$ i.d., $5 \mu \mathrm{m}$ ) (Agilent Technologies, USA). All of determination was followed the method of R. Tungpradit [15]. The mobile phases, which consist of $5 \%$ acetonitrile, $0.1 \%$ formic acid (A) and $95 \%$ acetonitrile in $0.1 \%$ formic acid in aqueous solution (B), which formic solution was adjusted $\mathrm{pH}$ at 4.5 using $\mathrm{NaOH}$, after that all solvents were filtered through a $0.45 \mu \mathrm{m}$ Milipore filter and degases before use. The HPLC condition was used the gradient program $0-35 \%$ B from $0-5 \mathrm{~min}, 36-60 \% \mathrm{~B}$ from $6-15 \mathrm{~min}$ and $61-100 \% \mathrm{~B}$ from $16-20 \mathrm{~min}$ after that, constantly $100 \% \mathrm{~B}$ for $10 \mathrm{~min}$, total time was $30 \mathrm{~min}$. The injection volume was $20 \mu \mathrm{L}$ at flow rate of $1 \mathrm{ml} \cdot \mathrm{min}^{-1}$. The Alk solution was monitored by measuring its absorption at $350 \mathrm{~nm}$.

\section{Preparation of Modified Bentonite}

The Na-Bent was prepared by dispersing into bottle with deionized water. The dispersion was modified by weight mixing with $\mathrm{BbrCl}$ or Alk by ratio (100:1, 200:1 and $500: 1, \% \mathrm{w} / \mathrm{w}$ ) in $25 \mathrm{ml}$ of aqueous solution, respectively. The mixtures were shaken continuously in room temperature at $160 \mathrm{rpm}$. After $24 \mathrm{~h}$, the resulting "organoclay" dispersion which was identified as BbrCl-Bent $1: 500,1: 200$ and 1:100 and AlkBent $_{1: 500,1: 200}$ and 1:100, the remains of $\mathrm{BbrCl}$ and $\mathrm{Alk}$ were washed by centrifuge at $25^{\circ} \mathrm{C}, 4000 \mathrm{rpm}$ for $30 \mathrm{~min}$. The supernatant was removed gently and sediment was dried at $105^{\circ} \mathrm{C}$ overnight. The dried sediment was grinded to powder and sieved using a 300-mesh sieve (Gallenkamp, London, US). Organoclays samples were kept in desiccators.

\section{E. Adsorption of Carbamate by Modified Bentonite}

200 ppm of carbaryl was used in overall treatments. The experiments were carried out in shaker at $160 \mathrm{rpm}$, for $24 \mathrm{~h}$. under room temperature. After equilibration, the dispersions were centrifuged at $4^{\circ} \mathrm{C}, 4000 \mathrm{rpm}$ for $30 \mathrm{~min}$ and collected the supernatant for next experiment. The amount adsorbed was calculated from the different concentration between initial and the equilibrium solution. Triplicates of each adsorption were used in all series of experiments. The concentration of carbaryl was determined by HPLC method.

\section{F. HPLC Analysis of Carbaryl}

Supernatant of carbaryl was collected, after centrifuge at $4000 \mathrm{rpm}$ for $30 \mathrm{~min}$ at room temperature, after that the residue was centrifuge again at $12,000 \mathrm{rpm}$ for $5 \mathrm{~min}$ to removed the dedicated particle. Solution samples were diluted for 4 times by deionized water and filtered + all samples with $0.45 \mu \mathrm{m}$ filter paper for preparing HPLC technique. The profile system for analysis of carbaryl was followed by R. Tungpradit method, the observation wavelength was on $280 \mathrm{~nm}$.

\section{G. Scanning Electron Microscopy Measurement}

The surface morphology of Ca-Bent, Na-Bent, BbrCl-Bents and Alk-Bents were observed under scanning electron microscopy (SEM) instrument (JEOL, JSM 5910 LV, Techniques LTD., Japan). Samples were coated by gold as a conductive material. Accelerating voltage at $15 \mathrm{kV}$ and 10,000 time magnification were applied.

\section{RESULTS AND DISCUSSIONS}

\section{A. Alkaloid Berberine Extraction from C. Fenestratum}

The yellowish-brownish precipitate which collected from centrifuge after dryness was $236 \mathrm{mg}(0.23 \%$ weight $)$ as in Fig. 1. In order to screen for alkaloid, the precipitate was analyzed by TLC. The orange-brown zone was occurred on paper that corresponded to alkaloid compound in precipitate could be observed.

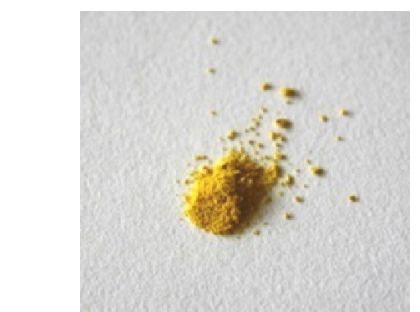

Fig. 1. Alkaloid extract from C. fenestratum

After precipitate was responded positively results for developing reagent, Alk precipitate was continued to quantified berberine compound by HPLC. $\mathrm{BbrCl}$ was used as a standard compound to compare the content of berberine in the Alk precipitate.

\section{B. Confirmation of Berberine in Alkaloid Extract}

The confirmation of berberine content by HPLC in Alk precipitate is illustrated in Fig. 2. The signal was indicated only one major peak in both chromatograms. The retention time $\left(t_{R}\right)$ of standard $\mathrm{BbrCl}$ was 16.990 min (Fig. 2a) and quite similar peak at retention time 17.058 was belongs to Alk precipitate in methanol (Fig. 2b). Comparison the retention time between $\mathrm{BbrCl}$ and alk precipitate chromatograms were showed non-significantly difference time shift, assume that Alk was contained berberine compound about $70 \%$. The other peaks after these could not 
be identified, probably using high performance techniques to carried out.

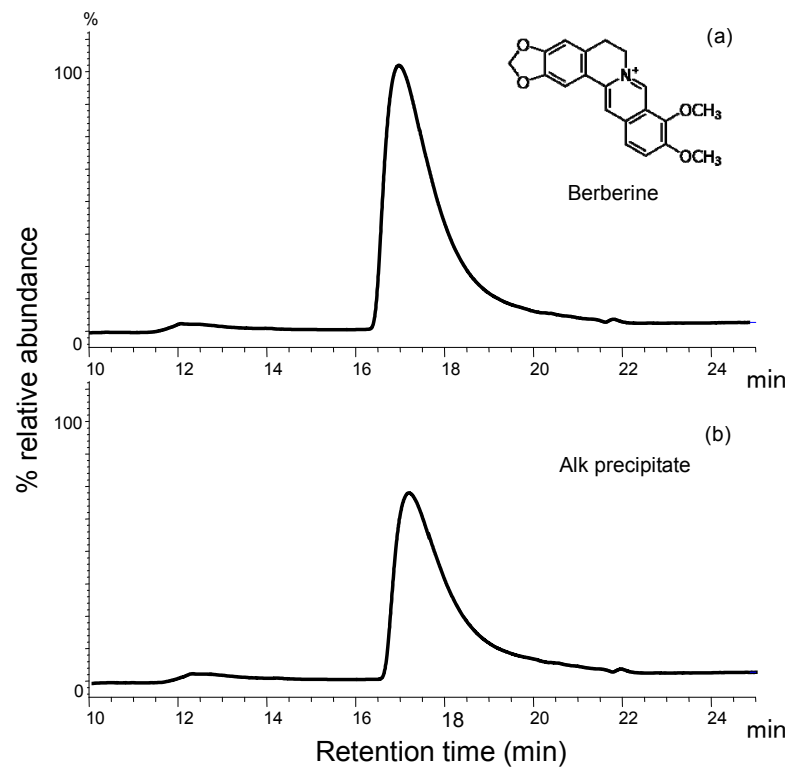

Fig. 2. HPLC chromatograms of standard $\mathrm{BbrCl}$ (a) compared with berberine content in Alk precipitate. (b) The HPLC elution profile was recorded at 350 $\mathrm{nm}$.

\section{Modification of Commercial Bentonite}

In the part of modification into Ca-Bent and Na-Bent, the morphology of both $\mathrm{Ca}-\mathrm{Bent}$ and $\mathrm{Na}-\mathrm{Bent}$ was observed using SEM in Fig. 3 (x10,000). The Ca-Bent layer before modification demonstrated the wild plate form and less basal space as in Fig. 3a. The sheets of Na-Bent after modified with $\mathrm{NaCl}$ was exhibited more delicate than Ca-Bent, the space and layer sheets were increased which mean that Na-Bent should be adsorb water or liquid higher than Ca-Bent, follow by their called $\mathrm{Na}$-Bent is swelling-clay.
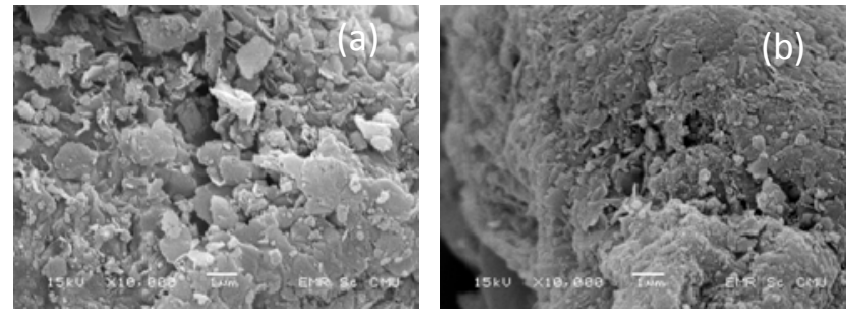

Fig. 3. SEM image showed the morphological surface of Ca-Bent before modification with $\mathrm{NaCl}$ (a) and Na-Bent which morphology was changed after modification with $\mathrm{NaCl}(\mathrm{b})$.

\section{Determination of Carbamate of Clay Modification}

The triplicate dispersions of each organoclay; BbrCl-Bent and Alk-Bent were exhibited changing physical properties after modification treatment with $\mathrm{BbrCl}$ and Alk precipitate for $24 \mathrm{~h}$ was finished. The color of dispersion which was changed from natural gray to gray-yellowish that belongs to $\mathrm{BbrCl}$ and $\mathrm{Alk}$ intercalation colors. The strongest yellowish was appeared on BbrCl-Bent $1: 100$ in Fig. $4 \mathrm{a}, \mathrm{BbrCl} \mathrm{Bent}_{1: 200}$ and BbrCl-Bent ${ }_{1: 500}$ and the Alk-Bent samples were indicated same ratio which was $1: 100,1: 200$ and 1:500, respectively (Fig. 5b). After drying process overnight, all organoclays was observed as still gray-yellowish and easier to grinded to powder, that could explain the intercalation of $\mathrm{BbrCl}$ or Alk into space of bentonite, and expanding the inter space of bentonite comparing with $\mathrm{Na}-\mathrm{Bent}$ before treatments.

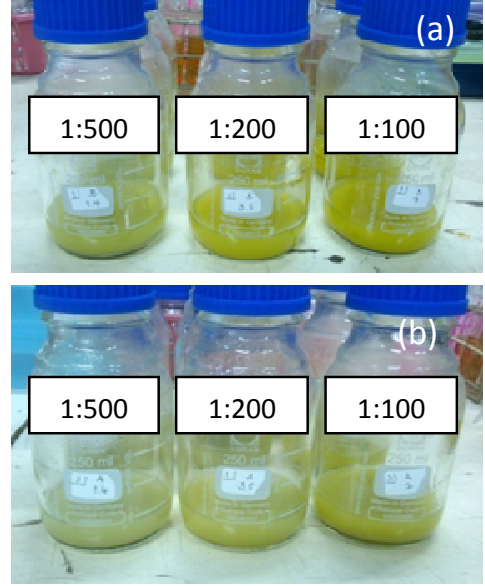

Fig. 4. Suspension samples after treatment of $\mathrm{Na}-\mathrm{Bent}$ with $\mathrm{BbrCl}$ (a), from left to right; $\mathrm{BbrCl}-\mathrm{Bent}_{1: 500}, \mathrm{BbrCl}_{1: 200}, \mathrm{BbrCl}_{1: 100}$ and Na-Bent with Alk precipitate (b), from left to right; Alk-Bent ${ }_{1: 500}$, Alk-Bent $_{1: 200}$, Alk-Bent $_{1: 100}$.

\section{E. Determination of HPLC Analysis}

The carbaryl pesticide adsorption by organoclays after modifies with $\mathrm{BbrCl}$ and $\mathrm{Alk}$ were determined by using HPLC technique. The HPLC graphs demonstrate the residue of carbaryl which could not be adsorb by organoclay treatments. The retention time of carbaryl and standard carbaryl were occurred as the same retention time at $\sim 9.0 \mathrm{~min}$ (data not shown). Fig. 5 illustrates the adsorption capabilities of different modified bentonite samples. Data showed the higher adsorption of modified bentonite Alk precipitate, the increasing at $7 \%$ of Alk-Bent compared with reaction control at the adsorption percentage at $77 \%$ after treatment on ratio 1:100 was the highest data among Alk-Bent samples. However, the ratio is not quite difference with the Alk-Bent $_{1: 500}$ at 5\% and the Alk-Bent ${ }_{1: 200}$ were demonstrated the lowest value of adsorption pesticide at $2 \%$ in total reaction. On the other hand, bentonite which modified with $\mathrm{BbrCl}$ was carried out the most increasing percentage adsorption at $24 \%$ belongs to BbrCl-Bent 1:200 $_{\text {after with }}$ BbrCl-Bent $_{1: 500}$ and BbrCl-Bent $1: 100$ at $19 \%$ and $3 \%$ respectively. The excess obtaining of $\mathrm{BbrCl}$ or $\mathrm{Alk}$ precipitate in the reaction can decrease the adsorption capability because the berberine was supposed to be saturated in the space of clay may block the carbaryl sorption process.

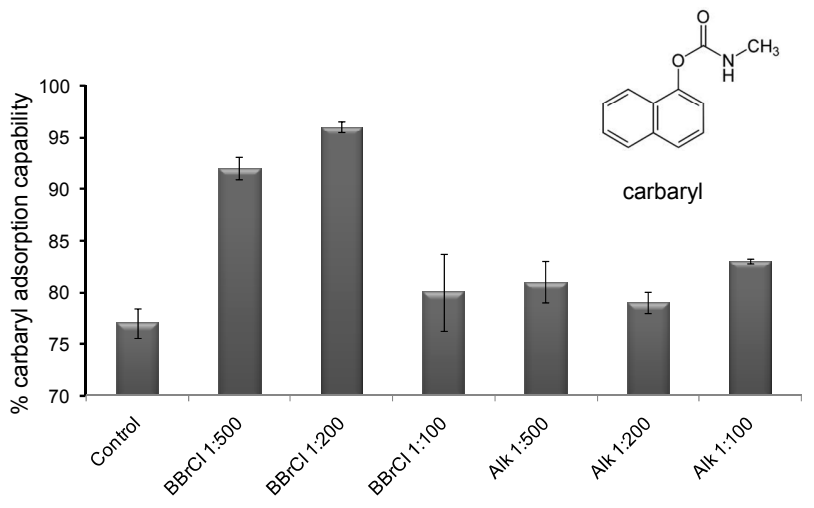

Fig. 5. The carbaryl adsorption capability of modified BbrCl-Bentonite and Alk-Bentonite.

\section{F. Electron Microscopy}

The morphology of non-swelling bentonite or Ca-Bent was not changed after modification to swelling Na-Bent (Fig. 3). New reflection appeared after modification, by $\mathrm{BbrCl}$ and 
Alk. The distance between blocks was expanded between the smectite layers. The surface of organoclays in Fig. 6a-b is differed from the original bentonite. The micrographs of modified samples reveal another deposited phase on the grinded of original minerals which explain both berberine standard compound and natural berberine extracted can intercalate into the space of smectite interlayer and change their surface morphology of modified organoclays.

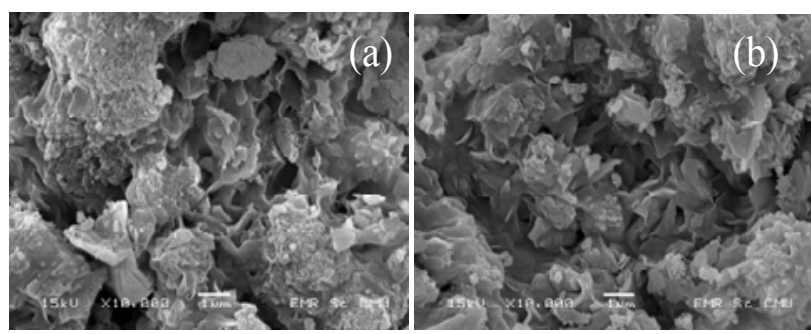

Fig. 6. Scanning electron microscopy images of BbrCl-Bent $\mathrm{B}_{1: 200}$ (a), Alk-Bent $_{1: 100}$ (b), the maximum capability of adsorption after modified with $\mathrm{BbrCl}$ and Alk precipitate.

\section{CONCLUSION}

This study investigated the ability modified bentonite with berberine to adsorb carbamate pesticide; carbaryl. The bentonite modifications by natural extract from C. fenestratum containing berberine can change the morphology of commercial bentonite, and enhance the carbaryl adsorption of the "organoclay" berberine-sodium-bentonite. SEM analysis of this material showed the expanding basal space onto interlayer of clay and maximum ratio of $\mathrm{BbrCl}-\mathrm{Bent}$ at 1:200 and Alk-Bent at 1:500 that related to the bentonite modification and its higher adsorption to carbaryl. The higher ratio might cause the saturated of $\mathrm{BbrCl}$ or Alk precipitate in the layer of clay and occurring the decreasing the adsorption capability.

Taken into account, modified bentonite by natural alkaloid such as berberine could generate a new ideal material to adsorb carbamate pesticide effectively. It could be applied to clean-up pesticide residue in agricultural water zone and products. The new material based on the combination between berberine and bentonite is not only easy to produce but also brings a low-cost material in term of economy.

\section{ACKNOWLEDGMENT}

The authors would like to thank Department of Chemistry, Faculty of Science, Chiang Mai University, for their instruments and chemicals support.

\section{REFERENCES}

[1] M. Vandekar, R. Plestina, and K. Wilhelm, "Toxicity of carbamates for mammals," Bulletin of the World Health Organization, vol. 44, pp. 241-249, 1971.

[2] G. Lagaly, "Pesticide-clay interactions and formulations," Applied Clay Science, vol. 18, pp. 205-209, May 2001.

[3] P. F. Luckham and S. Rossi, "The colloidal and rheological properties of bentonite suspensions," Advances in Colloid and Interface Science, vol. 82, pp. 43-92, Oct 1999.

[4] M. Ul-Islam, T. Khan, and J. K. Park, "Nanoreinforced bacterial cellulose-"montmorillonite composites for biomedical applications," Carbohydrate Polymers, vol. 89, pp. 1189-1197, Aug 2012.

[5] M. Randelovic, "Synthesis of composite by application of mixed Fe, $\mathrm{Mg}$ (hydr)oxides coatings onto bentonite -A use for the removal of $\mathrm{Pb}$ (II) from water," Journal of Hazardous Materials, vol 199, pp. 367-374, Jan 2012

[6] C. H. Hu, "Effects of $\mathrm{Cu} 2+$-exchanged montmorillonite on growth performance, microbial ecology and intestinal morphology of Nile tilapia (Oreochromis niloticus)," Aquaculture, vol. 270, pp. 200-206, Sep 2007.

[7] G. Ozdemir, M. H. Limoncu, and S. Yapar, "The antibacterial effect of heavy metal and cetylpridinium-exchanged montmorillonites," Applied Clay Science, vol 48, pp. 319-323, Apr 2010.

[8] S. Mirmohamadsadeghi, "An efficient method for clay modification and its application for phenol removal from wastewater," Applied Clay Science, vol. 59, pp. 8-12, May 2012.

[9] S. Gitipour, M. T. Bowers, and A. Bodocsi, "The Use of Modified Bentonite for Removal of Aromatic Organics from Contaminated Soil," Journal of Colloid and Interface Science, vol. 196, pp. 191-198, Dec 1997.

[10] B. Indira, and L. Civil, Indian Minerals Year book 2011, 50th ed. Government of India, IN.: Indian Bureau of Mines, 2012, pp. 2-7.

[11] O. sarapaa, A. Thair, Clay and Clay Mineralogy; Finland: Tutkuskeskus, 2008, pp. 2-7.

[12] P. Rojsanga, and W. Gritsanapan, "Variation of Berberine Content in Coscinium fenestratum Stem in Thailand Market," Mahidol University Journal of Pharmaceutical Sciences, vol. 32, pp. 66-70, Oct 2005.

[13] J. Yin, J. Ye, and W. Jia, "Effects and mechanisms of berberine in diabetes treatment," Acta Pharmaceutica Sinica B, vol. 2, pp. 327-334, Aug 2012.

[14] Y. Zhang, "Berberine increases the expression of NHE3 and AQP4 in sennosideA-induced diarrhoea model," Fitoterapia, vol. 83, pp. 1014-1022, Sep 2012.

[15] R. Tungpradit, S. Sinchaikul, and S. Phutrakul, "Antiproliferative activity of berberine from Concinium fenestratum on NCI-H838 cell line," Chiang Mai J.Sci, vol 38, pp. 85-94, May 2011.

[16] P. Rojsanga, W. Gritsanapan, and L. Suntornsuk, "Determination of Berberine Content in the Stem Extracts of Coscinium fenestratum by TLC Densitometry," Medical Principles and Practice, vol. 15, pp. 373-378, May 2006.

[17] G. Rytwo, "Adsorption of berberine on commercial minerals" Applied Clay Science, vol 51, pp. 43-50, Jan 2011.

[18] A. N. Chulkov, "The influence of clay surface modification with berberine on the sorption of anthocyanins," Russian Journal of Physical Chemistry A, vol 86, pp. 429-431, Mar 2012.

[19] L. Jianfa, L. Yimin, and L. Jinhong, "Adsorption of herbicides 2,4-D and acetochlor on inorganic-organic bentonites," Applied Clay Sciences, vol. 46, pp. 314-318, Nov 2009.

[20] Sreevidya, Narasimhan, Mehrotra, Shanta, "Spectrophotometric method for estimation of alkaloids precipitateblewith dragendorff's reagent in plant materials," Journal of AOAC international, vol. 86, pp. 1124-1127, Nov 2003

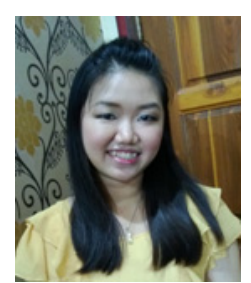

Suphara Tha-in was born in 1988, Chiang Mai, Thailand. She received Bachelor degree in Applied Chemistry (Natural product), School of Science, Mae Fah Luang University, Chiang Rai, Thailand. And now, she is studying in Chemistry program, Graduate School, Department of Chemistry, Faculty of Science (2010-present) at Chiang Mai, University, Thailand.

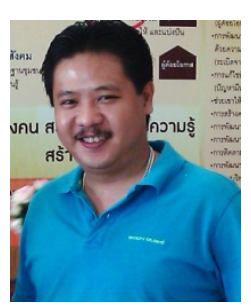

Dau Hung Anh was born in 1976, Hanoi, Vietnam. $\mathrm{He}$ received the B.Sc and $\mathrm{M}$. Sc degrees in Biotechnology from Hanoi National University, Vietnam and Dr. rer. nat. in microbiology from International Graduate School of Zittau, Germany. $\mathrm{He}$ is now instructor at Rajamangala University of Technology Lanna, Chiang Mai, Thailand. His research interests are biocatalyst and bioactive compounds towards applied environmental biotechnology.

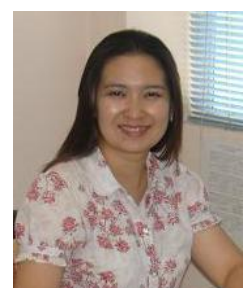

Kanchana Dumri was born in 1976, Chiang Mai, Thailand. She graduated the B.Sc ( $1^{\text {st }}$ Hons, Chemistry) from Chiang Mai University. She earned degree the M.Sc (Biotechnology) from Mahidol University, Bangkok, Thailand. Later, she got the Leibniz-DAAD scholarship from Leibniz Institute of Plant Biochemistry (Halle) Germany for her Ph.D. program.

She is now an instructor at Department of Chemistry, Faculty of Science, Chiang Mai University, Thailand. Her research interests are dealing with biodegradation of agricultural chemicals and development the biochemical test on-field for pesticides and bacterial pathogens detection. 